\title{
Leigh syndrome
}

INSERM

\section{Source}

INSERM. (1999). Orphanet: an online rare disease and orphan drug data base. Leigh

syndrome. ORPHA:506

Leigh syndrome or subacute necrotizing encephalomyelopathy is a progressive neurological disease defined by specific neuropathological features associating brainstem and basal ganglia lesions. 